\title{
Notetaking Instruction Enhances Students' Science Learning
}

\author{
Pai-Lin Lee, ${ }^{1}$ Chiao-Li Wang, ${ }^{2}$ Douglas Hamman, ${ }^{3}$ \\ Ching-Hsiang Hsiao, ${ }^{4}$ and Chuang-Hua Huang ${ }^{4}$ \\ ${ }^{1}$ Department of Educational Psychology and Counseling, National Pingtung University of Education, \\ Pingtung City 90003, Taiwan \\ ${ }^{2}$ Center for Teacher Education, National Kaohsiung Normal University Taiwan, Kaohsiung City 80201, Taiwan \\ ${ }^{3}$ Curriculum Studies and Teacher Education, Texas Tech University, 2500 E Broadway Lubbock, TX 79409, USA \\ ${ }^{4}$ Department of Early Childhood Education, Chia Nan University of Pharmacy and Science, Tainan City 71710, Taiwan
}

Correspondence should be addressed to Pai-Lin Lee; orientalpai@yahoo.com

Received 7 November 2012; Revised 20 February 2013; Accepted 21 February 2013

Academic Editor: Andrew N. Meltzoff

Copyright (c) 2013 Pai-Lin Lee et al. This is an open access article distributed under the Creative Commons Attribution License, which permits unrestricted use, distribution, and reproduction in any medium, provided the original work is properly cited.

Students face various learning challenges in their daily life. Teachers should teach them learning strategies to accommodate demands. One hundred ten fifth graders were randomly assigned to three groups: strategic notetaking, partial strategic notetaking, and control group, with three levels (high versus medium versus low) according to their prior science achievement. The levels also functioned as one independent variable in the MANCOVA analysis, with writing speed as covariate. The results showed significant treatment main effects in support of strategic and partial strategic groups on the measurements of board cued, verbal cued, and noncued information units. The high science achievement group outperformed the low one on the task of verbal cued, whereas the medium outperformed the low one on comprehension multiple-choice test. The study suggested notetaking as an effective learning strategy that can be taught to elementary students.

\section{Notetaking Instruction Enhances Students' Science Learning}

Knowledge, rather than manufactured product, has become the central economic commodity of our modern society [1]. And as noted over two decades earlier, "He who has access to knowledge has the power" (see [2, page 20]) and has the best chance to be successful [3]. Studies have shown that learners' limited knowledge of study skills is a major reason that encounters academic difficulty during secondarylevel schooling or in college $[4,5]$. In response to this situation, educators often recommend strategies instruction as a mean of enhancing the learning outcomes for children [6]. Moreover, the demands of knowledge transfer to novel contexts likewise recommend strategies instruction as a way to help students address future learning needs [7].

Many studies concerned with strategies instruction suggest that students should be taught that study skills produce positive effects on learning [8,9], should be taught early enough [10], and strategies such as summarizing and identifying main ideas from text and discourse are believed to be utmost important [11].

1.1. Notetaking Strategies. Much evidence indicates that teaching notetaking is an effective strategy to improve students' learning (e.g., [12-15]). Findings from this research indicate that frequency and quality of notetaking are positively correlated with students' academic performance [1619]. Notetaking may help students by "attending to the lecture, locating targets in long-term memory, holding and manipulating the attended information in working memory, encoding ideas into long-term memory, and transcribing relevant notions" (see [12, page 41$]$ ).

Researchers have concluded that students at all levels benefit from the instruction about how to learn, and many educators endorse the inclusion of strategies instruction in the school curriculum $[20,21]$. Learning strategies, such as notetaking, can be successfully taught to children as young as elementary age when planned well [14]. 
Previous notetaking research focused mainly on high school and college students $[16,22]$ seems to overlook the fact that children at primary schools are metacognitively capable of directing their own memory processes, organizing information, and paying attention to important information [23]. Accordingly, it is reasonable to assume that they may possess the cognitive capacities needed for notetaking. Left to their own devices, however, students tend not to be very proficient at taking notes (e.g., [24]), but many researchers assert that students can become effective notetakers by receiving systematic notetaking instruction from experts, then practicing it themselves and improving their notetaking by comparing their own notes with peers' [13].

1.2. Strategic and Partial Strategic Notetaking. There are many different approaches to notetaking that may assist students' learning new contents. The Strategic Notetaking method (see Appendices), which is characterized by written guides, encourages students to actively involve in the learning process and thus lead to an improvement on their performance of the test of long-term word recall [17]. In the Strategic Notetaking form, written prompts are provided to guide students in identifying main points, summarizing, and organizing lecture information $[16,17,22]$. This notetaking training has also been shown to be effective with students who have learning disabilities to improve the fluency with which they use the notetaking form [22]. As Boyle [16, 22] explained, the strategic notetaking form was developed expressly to affect metacognitive processes, such as organizing information and combining new and previous knowledge together, which facilitates generative learning.

Another tool intended to help students learn from class lecture is the Partial Strategic notetaking form adopted from Boyle's strategic notetaking $[16,22]$. This form is consisted of two parts: guided notes and cognitive load theory. Guided notes prompt students when and where to record critical information, which helps students improve the quality of their notetaking and academic performance [24, 25]. One study found that students who received partial notetaking instruction performed better on conceptual and application questions than complete notes [26].

Cognitive load theory also contributes to an understanding of why notetaking instruction may be effective. Atkinson and Shiffrin's [27] information processing theory suggests that information is processed in the short-term memory, which has a limited capacity for processing information. When overloaded, some information may be dropped out of it of working or short-term memory [5]. According to cognitive load theory, then, a notetaking form may help reduce students' cognitive load thus giving them more cognitive space to process information presented in the lecture [28]. Katayama and Robinson [29] argued that by providing $50 \%$ of the information in the partial graphic organizer, students would experience a lessened cognitive load and lesser learning difficulty.

1.3. Prior Knowledge. According to Pressley and McCormick [30], knowledge provides grist for the strategy mill, which implies that some strategies can only be performed if other related knowledge has already been acquired. They argued that students with higher prior knowledge on certain subjects learn much better than students with lower prior knowledge, because prior knowledge activates relevant schema. Once a schema is activated, it helps the learners focus their attention on information and allows inferences, which enhances learning. However, the use of a learning strategy, coupled with prior knowledge, can maximize learning, as Pressley and McCormick pointed out: "even if students make some automatic associations to prior knowledge as they do a task, that does not mean that learning might not be improved additionally using strategies" (page 84).

Although there is evidence to suggest that prior knowledge facilitates the effectiveness of, and the use of strategies to learn, little is known about the way prior knowledge may be related to the learning of a new strategy. In the present study, the researchers investigated how students' prior knowledge affects students' achievement and responsiveness to notetaking instructions.

\section{Methods}

2.1. Participants. Participants in this study were 117 fifthgrade students in the natural science classes offered in a rural elementary school in southern Taiwan. The students' ages ranged from 11 to 12 years old. Seven students' data were omitted because they did not attend full training sessions. The remaining 110 children (females $=48$; males $=62$ ) were randomly assigned to three groups: the strategic, also as full notetaking, the partial strategic note taking, and the control condition.

2.2. Measurements. In order to examine the influence of prior knowledge on students' responsiveness to notetaking instruction, we utilized three types of dependent variables. The first type was derived from an analysis of three specific categories of cued content found in students' notes. The second was based on students' performance on a content-knowledge test. The third type of measure involved students' performance on a delayed recall task. In addition to these dependent variables, students' handwriting speed, as determined by the amount of time taken to write their name three times, was used as a covariate.

2.2.1. Prior Knowledge. The students' mid-term science performance on the last semester was used as criteria, so that three levels (high, medium, and low) were obtained on this variable.

2.2.2. Board-Cued Information Units (BCIU). These units were defined as the frequency of recorded content reflecting critical points of the presentation that were written on the chalkboard in the videotape lecture. In order to determine the frequency of board-cued information units, students' notes were collected and scored for the number of BCIU. The total possible score for BCIU was 12 , and one point was assigned 
for each instance of a recording in participants' notes of any portion of the cued information. Interrater reliability was calculated to be 0.97 for judgments of occurrences of BCIU.

2.2.3. Verbal-Cued Information Units (VCIU). These units were defined as the frequency of recorded critical content that was repeated by the presenter (i.e., stated two times consecutively) during the lecture. The total number of VCIU was 6 , and as before, one point was assigned for each instance of a recording in participants' notes of any portion of the cued information. Interrater reliability was calculated to be 0.95 for judgments of occurrences of VCIU.

2.2.4. Noncued Information Units (NCIU). These units were defined as the number of information units orally delivered only once by the teacher without any emphasis, either verbally or written on the board. The total number of NCIU was 8 , and one point was assigned for each instance of a recording in participants' notes of any portion of the cued information. Interrater reliability was calculated to be 0.95 for judgments of occurrences of NCIU.

2.2.5. Test of Students' Content Knowledge. A traditional classroom test was developed in order to assess students' knowledge. This test consisted of 15 multiple-choice items and three short-answer essays. Multiple-choice items were developed based on factual information presented in the lecture. Students received one point for each correct answer, resulting in a total possible score of 15 points. The internal reliability of this portion of the assessment was within an acceptable range $(\alpha=.76)$. Three short-answer essay questions were also developed consisting of questions intended to probe students' understanding and higher-order thinking [31, 32] of the videotaped lecture. One point was added to students' scores for each correct response given, resulting in a total score for essay items of three points. The internal reliability of this portion of the assessment was within an acceptable range $(\alpha=.80)$.

2.2.6. Long-Term Free Recall (LTFR). The assessment was administered $48 \mathrm{hr}$ after viewing the videotaped lecture. Students were provided with a blank paper for recording the concept items and allowed five minutes to recall and record as much of the lecture content as possible. One point was given for each concept recorded resulting in a total possible recall score of 26. Interrater reliability of LTFR was assessed. Two independent rater scores of students' responses were correlated at 95 .

2.2.7. Handwriting Speed. The words per minute (WPM) method was used for ascertain students' handwriting speed. Students were asked to write their names three times, and the resulting score corresponded to the length of time needed to write their name. This task was selected due to the fact that little or no cognitive processing is required to perform this task [19].
2.3. Procedure. The procedures for this study include the delivery of notetaking strategies training and the administration of the assessments previously described.

2.3.1. Training Session. Participants in the two treatment groups received identical training with the exception of different types of notetaking strategy (i.e., full notetaking versus partial notetaking strategies). A same instructor/researcher instructed five training sessions ( $40 \mathrm{~min}$ each) appropriately for the specific notetaking strategy. For each treatment condition, the instructor provided students with information about declarative, procedural, and conditional knowledge related to the use of the strategy [13]. Each training session also included opportunities for students to practice the notetaking strategy. Practice consisted of watching a short, $10 \mathrm{~min}$ videotaped lectures on air quality and burning, during which students would practice the specific notetaking skill. At the end of each session, the researcher collected students' notes, selected three best notes by their quality and quantities, and verbally praised the chosen notetakers for their efforts. The example notes were then shown to the other students for modeling purposes.

2.3.2. Assessment Session. At the sixth session, all participants watched a new, 10-minute science videotape on forces and exercise. Students were encouraged to take notes as they had been taught. At the end of the videotaped lecture, students were given 10 more minutes to study and review their notes, then the notetaking forms were collected and analyzed. After this review period, the content knowledge assessment was administered. Participants were allowed 10 minutes to complete a multiple-choice quiz and 6 minutes to complete the short-answer essay items. Two days later, at the seventh session, each group of students was administered the longterm free recall test in which students were given 5 minutes to list as many of the topic-related concepts that they could remember from the videotape.

\section{Results}

3.1. Preliminary Analysis. As a preliminary step in the analysis, data were screened. Only one outlier was found, and six data records were omitted because the students were absent from at least one of the training sessions. Based on results from tests of skewedness and kurtosis, assumptions about the normality of distribution were supported [33]. A further examination of the oval-shaped scatter plots of the four dependent variables indicated the existence of linearity relationship. The correlation between all the dependent and independent variables was low thereby indicating nonmulticollinearity [34]. The test for homogeneity of dispersion matrices was not significant, and the homogeneity assumption was met [35].

\subsection{Examining Effects of Prior Knowledge on Responsiveness} to Notetaking Training. The purpose of this study was to examine the extent of differences in students' prior knowledge related to their response to notetaking instruction 
as operationalized in their use of effective notetaking strategies. A $3 \times 3$ MANCOVA was conducted with treatment (i.e., type of notetaking instruction) and prior knowledge (high, medium, and low) as the independent variables, writing speed as the covariate, and the six dependent variables: (a) BCIU (board-cued information unit), (b) VCIU (verbal-cued information unit), (c) NCIU (noncued information unit), (d) total score on a 15-item multiple-choice comprehension test, (e) total score on three essay questions, and (f) LTFR (longterm free recall) of concepts.

Results from this analysis revealed significant main effects for both treatment (type of notetaking instruction) (Wilks' $\lambda=.64, F(12,190)=3.99, P<.001)$ and prior knowledge (Wilks' $\lambda=.77, F(12,190)=2.27, P=.01$ ), but no significant interaction effects were found.

Univariate analysis was conducted as followups to the significant treatment main effect in the multivariate analysis. These results revealed significant differences for BCIU, $\left(F(2,100)=18.78, P=.00, \eta^{2}=.27\right) ; \operatorname{VCIU},(F(2,100)=$ $\left.4.51, P=.01, \eta^{2}=.08\right)$; and NCIU, $(F(2,100)=3.01, P=.05$, $\left.\eta^{2}=.06\right)$. Post-hoc pairwise comparisons with Tukey method revealed that full notetaking strategy group with means of ( $M=5.52,1.40$, and 1.59), outperformed the control groups $(M=1.39, .77,1.03)$ on the tasks of BCIU, VCIU, and NCIU, with $P<.001, P<.01$, and $P<.05$, respectively (Table 1 ). Similarly, students in the partial strategic notetaking group $(M=4.97,1.29$, and 1.31) outperformed control group on the same tasks, with $P<.001, P<.01$, and $P<.05$, respectively. No differences between full and partial notetaking treatments were found.

Following the significant main effect for prior knowledge in the multivariate analysis, univariate follow-up analyses were also conducted for each dependent variable. These analyses revealed that students with different levels of prior achievement performed differently on VCIU, $(F(2,100)=$ 4.28, $\left.P=.02, \eta^{2}=.08\right)$; Test, $(F(2,100)=4.31, P=.02$, $\left.\eta^{2}=.08\right)$; Essay, $\left(F(2,100)=4.00, P=.02, \eta^{2}=.07\right)$; and Concepts, $\left(F(2,100)=5.03, P=.01, \eta^{2}=.09\right)$. Post-hoc paired comparisons with Tukey method showed the high prior knowledge group with means of $(M=1.51)$ outperformed the low group $(M=.81)$ on the task of VCIU, $P=.01$, while, students in the medium prior knowledge group $(M=$ 11.33) outperformed low group $(M=9.27)$ on the task of Test, $P=.02$.

\section{Discussion}

Baxter et al. [36] claimed that notetaking has become increasingly popular in elementary science education (see also [21]). The present study examined the extent to which notebook writing might be enhanced through explicit instruction for notetaking, and the influence both the type of notetaking strategy taught students' prior knowledge might have on responsiveness to the notetaking instruction and the influence that instruction would have on comprehension and recall. In terms of the strategy training, we found that students in both treatment groups recorded significantly more cued and noncued information (good for review) during the lecture. Additionally, those students in medium prior knowledge level when receiving notetaking strategies outperform control group on the tasks of Test measurement. However, there were no significant differences between treatment and control participants in the measures of comprehension and recall.

The present study divided students into three various levels (high versus medium versus low) of prior knowledge groups to test the main effects and found that the high prior knowledge group did better only on VCIU, while the medium prior knowledge group did better on Test, both compared with low prior low group. The study has shown the potential of strategy instruction as an effective means to improve learning because of the positive relationship between the amount of information recorded in notes and previous academic performance $[22,37,38]$. Cognitive load theory also contributes to an understanding of why notetaking instruction may be effective. When overloaded, some information may be dropped out of it of working or shortterm memory [5]; it seems that overloaded effects tend to appear in lower priority students as evidence of lower VCIU performance in the current study.

Consistent with previous studies, the present study findings showed that the medium level prior knowledge students outperform their counterparts on Test (multiple-choice test) measurement. It has long been suggested that notetaking can alter a learner's cognitive process since it forces the student to listen, organize ideas, and relate material to his/her existing knowledge [39]. The current study findings suggested that the notetaking training program is effective to young students' learning.

Though the favorite outcomes were found on BCIU, VCIU, and NCIU variables, the notetaking training did not show significant effect on students' learning as measured by Test, comprehension (essay questions), and delayed free recall of information. The reasons for lacking differences might be due to that students are generally not good notetakers $[13,40]$ because the five training session might not be enough to scaffolding the sophistically notetaking behaviors for these nonsignificant effect tasks.

In addition, the results taking partial notes appearing to be more effective compared with full notes in college students [26] not found in the study by using the partial strategic notetaking format created by Boyle [22]. The reason that the results were different from Cornelius and OwenDeSchryver's might be due to the same reason of immatureness for partial notetaking method required more active cognitive efforts of notetakers.

The high prior knowledge group took more notes as measured by the VCIU, compared with the low one, and the medium prior knowledge group was also superior to the low one but only on Test. The reason for the lacking of significant effects on the rest variables might be due to the age of the participants who depend on structural instruction and guidance, for example, the teacher's explicit instruction on "write down this important information." This would be a practical implication for the fifth-grade teachers in the science classroom. Though the result seemed to indicate that the medium prior knowledge group students benefit the most 
TABLE 1: The means, standard deviation, and numbers of participants on dependant variables for the three treatments and two prior knowledge groups.

\begin{tabular}{|c|c|c|c|c|}
\hline Prior knowledge & Strategic $(N=38)$ & $\operatorname{Partial}(N=39)$ & Control $(N=33)$ & \\
\hline & & BCIU & & Total \\
\hline \multicolumn{5}{|l|}{$\operatorname{High}(N=33)$} \\
\hline$M$ & 6.80 & 6.25 & 1.33 & 4.80 \\
\hline SD & 2.69 & 3.41 & 2.50 & 2.86 \\
\hline$N$ & 12 & 12 & 9 & 33 \\
\hline \multicolumn{5}{|l|}{$\operatorname{Medium}(N=32)$} \\
\hline$M$ & 4.82 & 5.30 & 2.08 & 4.07 \\
\hline $\mathrm{SD}$ & 3.37 & 3.09 & 1.73 & 2.73 \\
\hline$N$ & 10 & 10 & 12 & 32 \\
\hline \multicolumn{5}{|l|}{ Low $(N=45)$} \\
\hline$M$ & 4.94 & 3.35 & .75 & 3.01 \\
\hline $\mathrm{SD}$ & 3.60 & 2.99 & .86 & 2.48 \\
\hline$N$ & 16 & 17 & 12 & 45 \\
\hline \multicolumn{5}{|l|}{ Total } \\
\hline$M$ & $5.52^{* *}$ & $4.97^{* *}$ & 1.39 & \\
\hline $\mathrm{SD}$ & 3.22 & 3.16 & 1.70 & \\
\hline \multirow[t]{2}{*}{$N$} & 38 & 39 & 33 & \\
\hline & & VCIU & & Total \\
\hline \multicolumn{5}{|l|}{$\operatorname{High}(N=33)$} \\
\hline$M$ & 2.00 & 1.33 & 1.22 & $1.51^{*}$ \\
\hline $\mathrm{SD}$ & 1.22 & .98 & .66 & .95 \\
\hline \multicolumn{5}{|l|}{ Medium $(N=32)$} \\
\hline$M$ & 1.06 & 1.50 & .83 & 1.13 \\
\hline $\mathrm{SD}$ & .96 & 1.08 & .83 & .96 \\
\hline \multicolumn{5}{|l|}{ Low $(N=45)$} \\
\hline$M$ & 1.13 & 1.05 & .25 & .81 \\
\hline SD & .80 & 1.02 & .45 & .76 \\
\hline \multicolumn{5}{|l|}{ Total } \\
\hline$M$ & $1.40^{* *}$ & $1.29^{* *}$ & .77 & \\
\hline \multirow[t]{2}{*}{ SD } & .99 & 1.03 & .65 & \\
\hline & & NCIU & & Total \\
\hline \multicolumn{5}{|l|}{$\operatorname{High}(N=33)$} \\
\hline$M$ & 1.80 & 1.33 & 1.00 & 1.38 \\
\hline SD & 1.30 & .77 & 1.00 & 1.02 \\
\hline \multicolumn{5}{|l|}{$\operatorname{Medium}(N=32)$} \\
\hline$M$ & 1.65 & 1.60 & 1.00 & 1.42 \\
\hline $\mathrm{SD}$ & 1.05 & 1.07 & 1.12 & 1.08 \\
\hline \multicolumn{5}{|l|}{ Low $(N=45)$} \\
\hline$M$ & 1.31 & 1.00 & 1.08 & 1.13 \\
\hline SD & .60 & .00 & .90 & .50 \\
\hline \multicolumn{5}{|l|}{ Total } \\
\hline$M$ & $1.59^{*}$ & $1.31^{*}$ & 1.03 & \\
\hline \multirow[t]{2}{*}{ SD } & .98 & .61 & 1.01 & \\
\hline & & Test & & Total \\
\hline \multicolumn{5}{|l|}{$\operatorname{High}(N=33)$} \\
\hline$M$ & 10.60 & 10.83 & 10.00 & 10.48 \\
\hline $\mathrm{SD}$ & 5.08 & 2.98 & 3.28 & 3.78 \\
\hline \multicolumn{5}{|l|}{$\operatorname{Medium}(N=32)$} \\
\hline$M$ & 11.76 & 12.40 & 9.83 & $11.33^{*}$ \\
\hline $\mathrm{SD}$ & 2.43 & 3.23 & 2.98 & 2.88 \\
\hline
\end{tabular}


TABle 1: Continued.

\begin{tabular}{|c|c|c|c|c|}
\hline Prior knowledge & Strategic $(N=38)$ & Partial $(N=39)$ & Control $(N=33)$ & \\
\hline \multicolumn{5}{|l|}{ Low $(N=45)$} \\
\hline$M$ & 9.44 & 9.88 & 8.50 & 9.27 \\
\hline $\mathrm{SD}$ & 3.27 & 3.18 & 3.82 & 3.42 \\
\hline \multicolumn{5}{|l|}{ Total } \\
\hline$M$ & 10.60 & 11.04 & 9.44 & \\
\hline \multirow[t]{2}{*}{ SD } & 3.59 & 3.13 & 3.36 & \\
\hline & & Essay & & Total \\
\hline \multicolumn{5}{|l|}{$\operatorname{High}(N=33)$} \\
\hline$M$ & 1.80 & 1.77 & 1.51 & 1.69 \\
\hline $\mathrm{SD}$ & 1.05 & .83 & .59 & .82 \\
\hline \multicolumn{5}{|l|}{ Medium $(N=32)$} \\
\hline$M$ & 1.16 & 1.98 & 1.85 & 1.66 \\
\hline $\mathrm{SD}$ & 1.07 & .80 & .25 & .71 \\
\hline \multicolumn{5}{|l|}{ Low $(N=45)$} \\
\hline$M$ & 1.13 & 1.46 & 1.04 & 1.21 \\
\hline $\mathrm{SD}$ & .68 & .72 & .75 & .72 \\
\hline \multicolumn{5}{|l|}{ Total } \\
\hline$M$ & 1.36 & 1.74 & 1.47 & \\
\hline \multirow[t]{2}{*}{ SD } & .93 & .79 & .65 & \\
\hline & & Delayed recall concepts & & Total \\
\hline \multicolumn{5}{|l|}{$\operatorname{High}(N=33)$} \\
\hline$M$ & 2.20 & 2.25 & 2.44 & 2.30 \\
\hline SD & 1.10 & 1.29 & 1.87 & 1.42 \\
\hline \multicolumn{5}{|l|}{$\operatorname{Medium}(N=32)$} \\
\hline$M$ & 2.35 & 2.40 & 2.30 & 2.35 \\
\hline $\mathrm{SD}$ & 1.37 & 1.37 & 1.88 & 1.54 \\
\hline \multicolumn{5}{|l|}{ Low $(N=45)$} \\
\hline$M$ & 1.99 & 2.11 & 1.83 & 1.98 \\
\hline $\mathrm{SD}$ & 1.70 & 1.41 & .93 & 1.35 \\
\hline \multicolumn{5}{|l|}{ Total } \\
\hline$M$ & 2.18 & 2.25 & 2.19 & \\
\hline SD & 1.36 & 1.36 & 1.56 & \\
\hline
\end{tabular}

from the notetaking instruction, more research is needed for further examining the effects of prior knowledge on the notetaking behaviors.

Contradicting to our original prediction, there was no significant interaction effect found between treatment and prior knowledge. Scaffolding effects by two notetaking skills were found to have no statistical difference between the low prior knowledge group and the higher prior achievement group. This, again, might be due to the complexity nature of notetaking behavior [13] which exhausts the cognitive function and lower cognitive load on the students of low prior knowledge group [28].

Just a reminder, that the notetaking skills might need to be supporting and scaffolding by various subject teachers. Even though some courses were offered to help students learn how to learn in the context of study skills courses [41-43], most researchers agree that it is better to offer the learning strategy instruction throughout the curriculum as part of the actual academic tasks that students encounter [21, 44].
This study provides evidence of the notetaking training program can benefit fifth-grade students learning science on certain aspects. The results confirm its effectiveness on successful learning as previous study suggested. Through careful design, we recommend all teachers, including those of young age, to incorporate the instruction as a formal program.

\section{Appendices}

A.

See Box 1.

\section{B. Test of Students' Content Knowledge (Sample Items)}

(1) Which of the following does not require force?

(1) Mom cutting fruit in the kitchen

(2) Workers moving the refrigerator 
Strategic notetaking form

What is today's topic?

Describe what you know about the topic.

Page 1

As the instructor lectures, use these pages to take notes from the lecture.

Today's topic?

Name three to seven main points with details of today's topic as they are being discussed.

Summary: quickly describe how the ideas are related.

New concept or terms:

Name three to seven new main points with details as they are being discussed.

Page 2

New concept or terms:

Summary: quickly describe how the ideas are related.

Name three to seven new main points with details as they are being discussed.

Page X

New concept or terms:

Summary: quickly describe how the ideas are related.

At end of lecture

Last Page

Write five main points of the lecture and describe each point.

$\downarrow$

5 .

Note: from "The effects of strategic notetaking on the recall and comprehension of lecture information for high school students with learning disabilities." By Boyle and Weishaar [17], learning disabilities research and practice.

Box 1: An abbreviated strategic notetaking form.

(3) A baby sleeping

(4) A girl biking up a hill

(2) Which of the following descriptions about force is wrong?

(1) The greater the force exerted, the more difficult it is to observe change in the object

(2) When arm-wrestling, the winner uses a greater amount of force

(3) The more force that is used, the longer the rubber band is stretched

(4) When kicking a ball, the more force is used, the further the ball rolls

(3) Which of the following actions uses force?

(1) Lifting a bucket

(2) Sleeping

(3) Playing the xylophone

(4) Watching the television

Essay questions

(1) List three examples of "force" used in your daily lives?

(2) List the different types of "forces."

\section{Acknowledgments}

The paper was supported by the National Science Council of Taiwan under Grant NSC 95-2413-H-041-002-. The opinions expressed in this paper are those of the authors and do not necessarily reflect the view of the funding agency.

\section{References}

[1] P. Sahlberg and D. Oldroyd, "Pedagogy for economic competitiveness and sustainable development," European Journal of Education, vol. 45, no. 2, pp. 280-299, 2010.

[2] A. Toffler, Powershift, Bantam Books, New York, NY, USA, 1990.

[3] A. Toffler and H. Toffler, Creating a New Civilization, Turner, New York, NY, USA, 1995.

[4] S. Graham and K. R. Harris, "Improving the writing performance of young struggling writers: theoretical and programmatic research from the center on Accelerating Student Learning," Journal of Special Education, vol. 39, no. 1, pp. 19-33, 2005.

[5] M. A. Rafoth, L. Leal, and L. DeFabo, Strategies for Learning and Remembering, NEA Professional Library, West Haven, Conn, USA, 1993.

[6] M. M. Steele, "Making the case for early identification and intervention for young children at risk for learning disabilities," Early Childhood Education Journal, vol. 32, no. 2, pp. 75-79, 2004.

[7] R. N. Singer, J. H. Cauraugh, G. Lucariello, and H. J. Brown, "Achievement in related psychomotor tasks as influenced by learning strategies," Perceptural \& Motor Skills, vol. 60, pp. 843846, 1985. 
[8] D. H. Schunk, Learning Theories: An Educational Perspective, Pearson Education, Upper Saddle River, NJ, USA, 4th edition, 2004.

[9] E. A. Pardini, D. P. Domiz, D. A. Forbis, and G. B. Pettis, "Parallel notetaking: a strategy for effective use of webnotes," Journal of College Reading and Learning, vol. 35, no. 2, pp. 38-55, 2005.

[10] M. Smith, R. Teske, and M. Gossmeyer, "Improving student achievement through the enhancement of study skills," ERIC Document Reproduction Service ED 441256, 2000.

[11] R. Marzano, D. J. Pickering, and J. E. Pollock, Classroom Instruction that Works: Research-Based Strategies for Increasing Student Achievement, ASCD, Alexandria, Va, USA, 2001.

[12] K. A. Kiewra, "Cognitive aspects of autonomous note taking: control processes, learning strategies, and prior knowledge," Educational Psychologist, vol. 23, no. 1, pp. 39-56, 1988.

[13] K. A. Kiewra, "How classroom teachers can help students learn and teach them how to learn," Theory into Practice, vol. 41, no. 2, pp. 71-80, 2002.

[14] P. L. Lee, W. Lan, D. Hamman, and B. Hendricks, "The effects of teaching notetaking strategies on elementary students' science learning," Instructional Science, vol. 36, no. 3, pp. 191-201, 2008.

[15] M. Weimer, "Should instructors provide students with complete notes?" The Teaching Professor, vol. 22, no. 6, p. 2, 2008.

[16] J. R. Boyle, "Thinking while notetaking: teaching college students to use strategic notetaking during lectures," in Innovative Learning Strategies: Twelfth Yearbook, B. G. Brown, Ed., pp. 918, International Reading Association, Newark, Del, USA, 1996.

[17] J. R. Boyle and M. Weishaar, "The effects of strategic note taking on the recall and comprehension of lecture information for high school students with learning disabilities," Learning Disabilities Research \& Practice, vol. 16, no. 3, pp. 133-141, 2001.

[18] A. M. Hayati and A. Jalilifar, "The impact of note-taking strategies on listening comprehension of EFL learners," English Language Teaching, vol. 2, no. 1, pp. 101-111, 2009.

[19] C. A. Hughes and S. K. Suritsky, "Note-taking skills of university students with and without learning disabilities," Journal of Learning Disabilities, vol. 27, no. 1, pp. 20-24, 1994.

[20] J. R. Boyle, "The process of note taking: implications for students with mild disabilities," The Clearing House, vol. 80, no. 5, pp. 227-230, 2007.

[21] A. U. Chamot, "Teaching learning strategies in immersion classrooms," The Bridge, 2001.

[22] J. R. Boyle, "Enhancing the note-taking skills of students with mild disabilities," Intervention in School and Clinic, vol. 36, no. 4, pp. 221-224, 2001.

[23] J. Trawick-Smith, Early Childhood Development, A Multicultural Perspective, Merril Prentice Hall, Upper Saddle River, NJ, USA, 2003.

[24] J. L. Austin, J. E. Carr, and M. Lee, "The effects of guided notes on undergraduate students' recording of lecture content," Journal of Instructional Psychology, vol. 31, no. 4, pp. 91-96, 2004.

[25] B. D. Lazarus, "Guided notes: effects with secondary and post-secondary students with mild disabilities," Education and Treatment of Children, vol. 16, pp. 272-289, 1993.

[26] T. L. Cornelius and J. Owen-DeSchryver, "Differential effects of full and partial notes on learning outcomes and attendance," Teaching of Psychology, vol. 35, no. 1, pp. 6-12, 2008.

[27] R. C. Atkinson and R. M. Shiffrin, "Human memory: a proposed system and its control processes," in The Psychology of Learning and Motivation, K. W. Spence and J. T. Spence, Eds., vol. 2, pp. 89-195, Academic Press, New York, NY, USA, 1968.
[28] J. Sweller and P. Chandler, "Evidence for cognitive load theory," Cognition and Instruction, vol. 8, pp. 351-362, 1991.

[29] A. F. Katayama and D. H. Robinson, "Getting students "partially" involved in notetaking using graphic organizers," The Journal of Experimental Education, vol. 68, pp. 119-133, 2000.

[30] M. Pressley and C. B. McCormick, Advanced Educational Psychology, Harper Collins college Publishers, New York, NY, USA, 1995.

[31] J. R. Criswell and S. R. Criswell, "Asking essay questions: answering contemporary needs," Education, vol. 124, no. 3, pp. 510-517, 2004.

[32] B. G. David, Tools for Teaching, Jossey-Bass Publishers, San Francisco, Calif, USA, 1993.

[33] A. J. Schwab, “Assumption of Normality. Data Analysis II," 2004, http://www.utexas.edu/courses/schwab.

[34] B. G. Tabachnick and L. S. Fidell, Using Multivariate Statistics, Allyn and Bacon, Boston, Mass, USA, 4th edition, 2001.

[35] S. B. Green and N. J. Salkind, Using SPSS for Windows and Macintosh, Prentice Hall, Upper Saddle River, NJ, USA, 3rd edition, 2003.

[36] G. P. Baxter, K. M. Bass, and R. Glaser, "Notebook writing in three fifth-grade science classrooms," The Elementary School Journal, vol. 102, no. 2, pp. 123-140, 2001.

[37] J. R. Boyle and D. Scanlon, Methods and Strategies for Teaching Students with Mild Disabilities, Houghton-Mifflin, Boston, Mass, USA, 2010.

[38] K. A. Kiewra and J. J. Fletcher, "The relationship between levels of notetaking and achievement," Human Learning, vol. 3, pp. 273-280, 1984.

[39] F. J. Di Vesta and G. S. Gray, "Listening and note-taking," Journal of Educational Psychology, vol. 63, pp. 8-14, 1972.

[40] B. B. Armbruster, “Taking notes from lectures," in Handbook of College Reading and Study Strategy Research, R. F. Flippo and D. C. Caverly, Eds., pp. 175-199, Lawrence Erlbaum Associates, Mahwah, NJ, USA, 2000.

[41] M. D. Gall, J. P. Gall, D. R. Jacobsen, and T. L. Bullock, Tools for Learning: A Guide to Teaching Study Skills, Association for Supervision and Curriculum Development, Alexandria, Va, USA, 1990.

[42] P. R. Pintrich, W. J. Mckeachie, and Y. G. Lin, “Teaching a course in learning to learning," Teaching of Psychology, vol. 14, no. 2, pp. 81-86, 1987.

[43] M. L. Simpson, C. R. Hynd, S. L. Nist, and K. I. Burrell, "College academic assistance programs and practices," Educational Psychology Review, vol. 9, no. 1, pp. 39-87, 1997.

[44] M. Pressley and V. Woloshyn, Cognitive Strategy Instruction, Brookline Books, Cambridge, Mass, USA, 1995. 

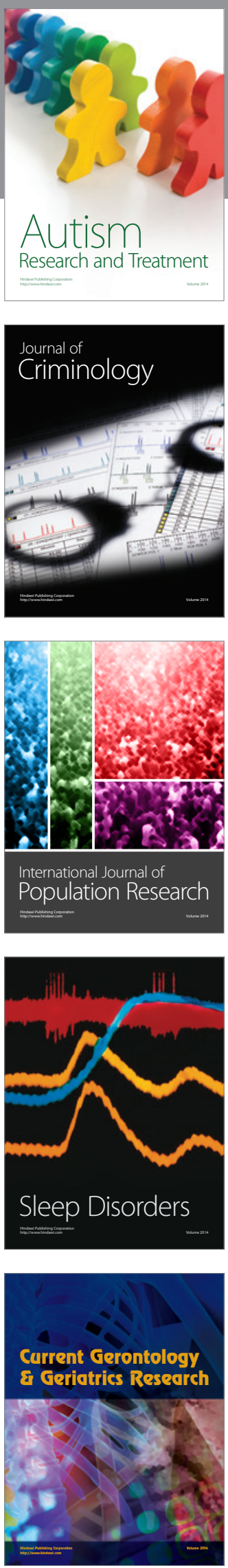
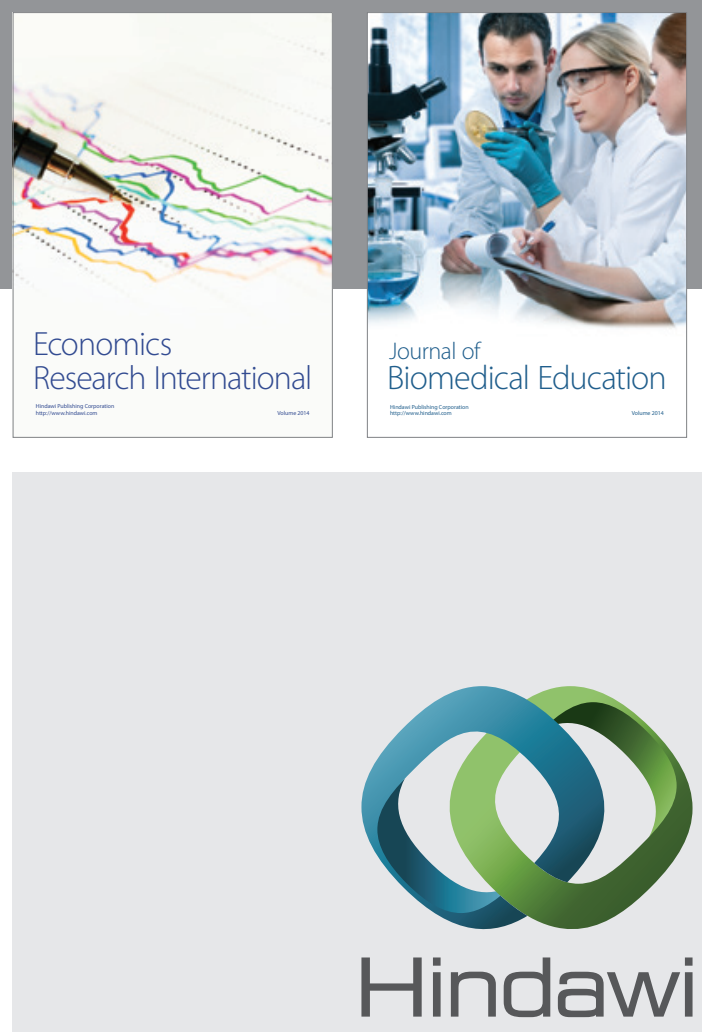

Submit your manuscripts at

http://www.hindawi.com
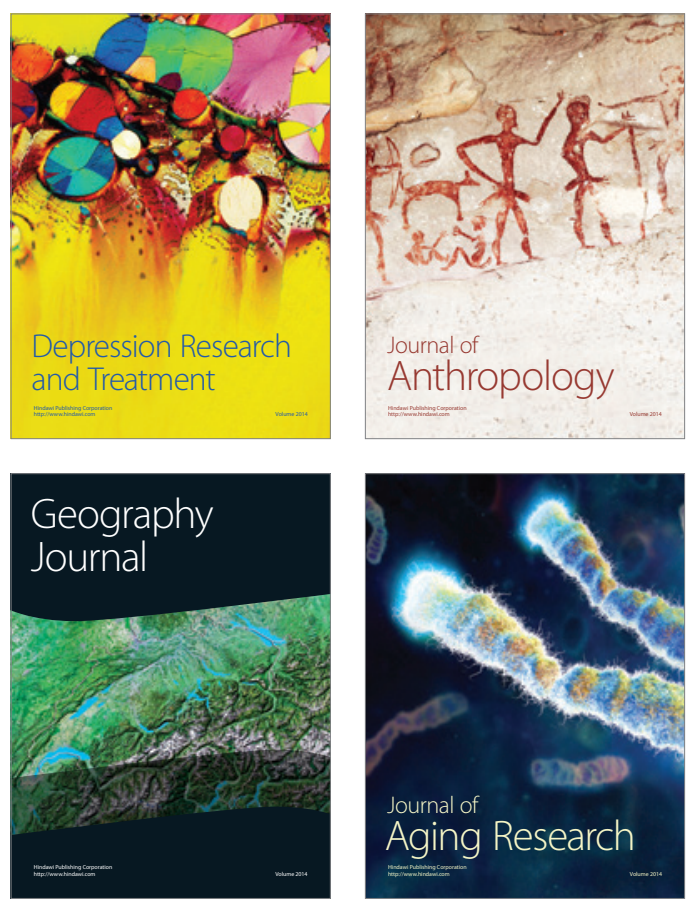
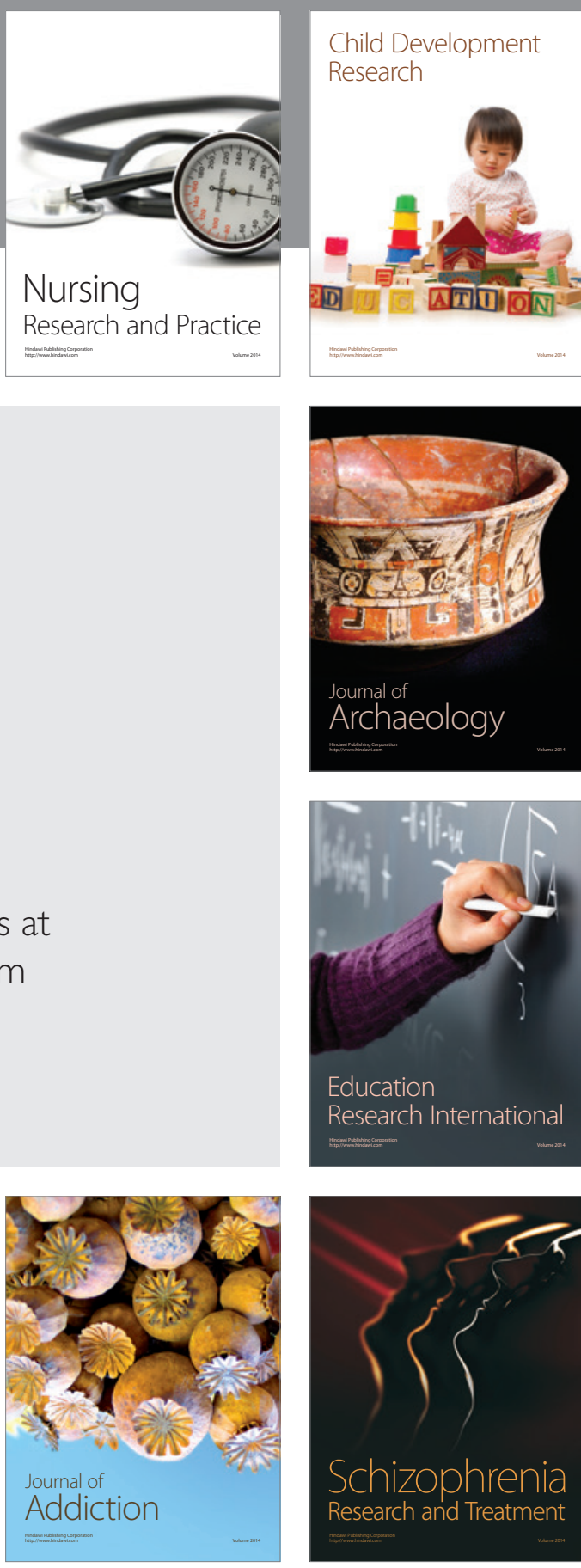

(D)
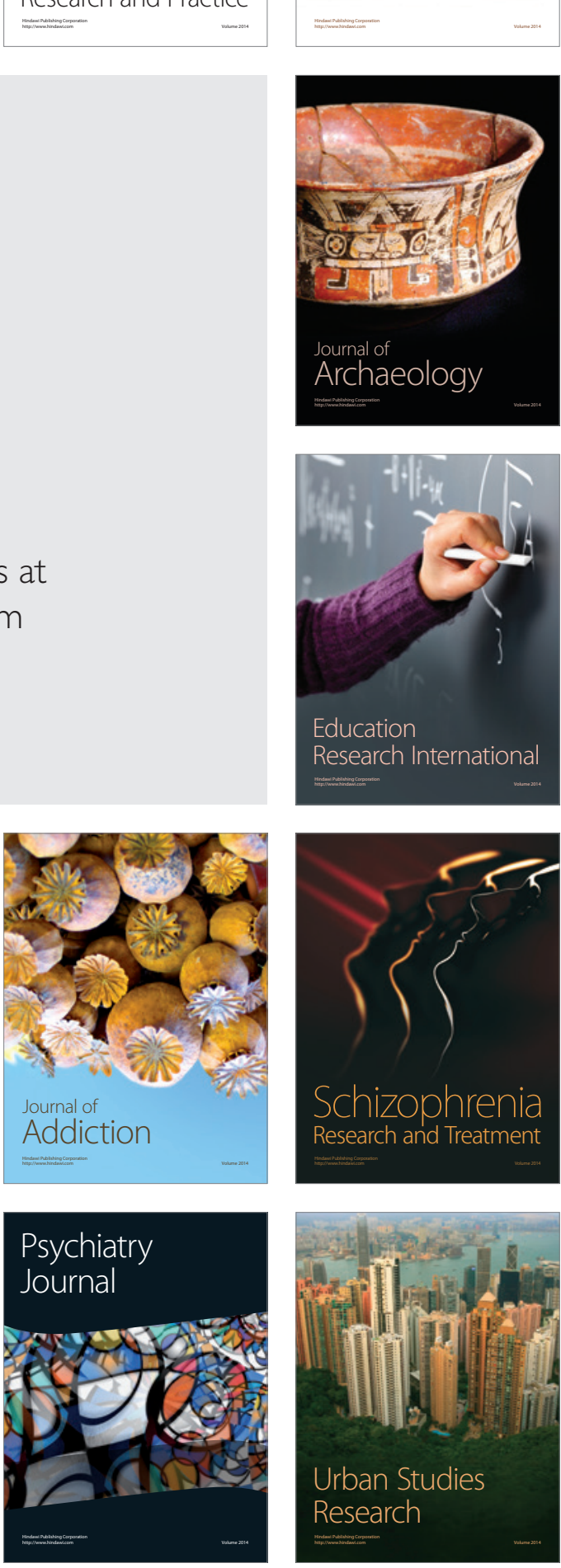